\title{
Fun and Engagement in Lecture Halls Through Social Gamification
}

https://doi.org/10.3991/ijep.v9i2.10163

Sebastian Mader $\left({ }^{\bowtie}\right)$, François Bry

Ludwig Maximilian University of Munich, Munich, Germany

sebastian.mader@ifi.lmu.de

\begin{abstract}
The traditional lecture is a teaching format which offers students few opportunities for engagement turning them into passive listeners of the lecturers' presentations what negatively impacts on their learning. With audience response systems, that is technology-supporting classroom quizzes, breaks which reactivate the students can be introduced into the lecturers' presentations. This article reports on an audience response system coupled with a social gamification of quizzes based on teams: Each student is assigned to a team and the students' answers to quizzes contribute to their team's success. An immediate overview of team participation updated in real-time during the quiz and updated team standings after the quiz are displayed for everyone to see motivating students to participate in the quizzes. The contribution of this article is threefold: First, a team-based social gamification of quizzes aimed at boosting participation in quizzes and attendance at lectures, second, original technological tools supporting the proposed team-based social gamification, and third, a first evaluation demonstrating its effectiveness in a small course and a second evaluation suggesting that for use in large classes teams have to be built in a specific way. This article is an extended version of [32] which provides a deeper representation of related work, a more extensive description of the team component, an additional evaluation, and implications for the use of the team-based social gamification in large classes.
\end{abstract}

Keywords-Gamification, audience response systems, online learning environments

\section{$1 \quad$ Introduction}

The traditional lecture - that is, a lecturer addressing an audience of variable size is a teaching format that offers students few opportunities for interaction: Asking questions and receiving answers is often the only possible form of interaction in a traditional lecture. As lecture audiences grow, students tend to ask less questions because of a well-known inhibiting social barrier: The larger the audience, the greater the fear of speaking out [22]. A vicious circle sets in: The students' reduced activity results in their reduced involvement what in turn results in their reduced learning performances [27] further contributing to reducing their activity. 
The reduced interactivity in traditional lectures can be addressed by slightly modifying the teaching format. A widespread approach consists in introducing breaks in the lecturer's exposition that are used for reactivating the students, for example by posing questions to the audience, so-called quizzes. While this is effective in lectures with small audiences of about twenty, this turns out hardly practicable with audiences of a few ten and fully impossible with audiences of a few hundred students. Indeed, collecting and aggregating the answers of large audiences are time consuming tasks that disrupt a lecture. Audience response systems overcome the obstacle by handing these tasks to software. While such a use of audience response systems in lectures enhances participation and provides a number of students with "active breaks", there are in our experience still students who remain passive and do not answer quizzes [19, p. 75], as well as students skipping lectures altogether. Indeed, regular or occasional absenteeism is another widespread problem of lectures [13]. The audience of a lecture generally drops by half during the semester and students that skip lectures try to discover, understand, learn, and practice lectures' contents one or two weeks or even only a few days before the lectures' examinations what mostly results in failure in the examination.

With the aim of improving both participation in quizzes and attendance at lectures, a gamification scheme with a social component, referred to in the following as "social gamification", has been devised. Social gamification is comparable to Nicholson's [18] engagement dimension. With the proposed social gamification scheme, students are assigned to teams that compete against each other in quizzes run during lectures. Each team member gives an individual answer, thus fostering the personal involvement necessary for an effective learning, but by doing so contributes to their team's performance. While a quiz is run, an overview of team participation updated in realtime and after a quiz updated team standings are displayed using a projector to foster among students a sense of responsibility for their teams' participation and achievements. This article describes this social gamification of the lecture hall and reports on two experiments, one experiment pointing to both the effectiveness of the approach and its positive reception by students in a small course while the second experiment exposes problems with the use of social gamification in courses with a large number of students. Issues of the approach in the second evaluation are identified and an approach tackling those issues is introduced.

The contribution of this article is threefold: First, a team concept aimed at boosting participation in lecture quizzes as well as attendance during lectures, second, original technological tools supporting the proposed team-based social gamification of quizzes, and third, two evaluations of the approach, one demonstrating its effectiveness for small lectures, the second one providing starting points on how to make teams work for large classes.

This article is structured as follows: Section 1 is this introduction. Section 2 is devoted to related work. Section 3 gives a general overview of the concepts behind the team component and the interface elements supporting the team component. Section 4 introduces the courses during which the team component has been evaluated and presents the results of the evaluations. Section 5 introduces an approach for teams in 
large classes using the results from both evaluations. Section 6 concludes the article and gives perspectives for future work.

\section{Related Work}

The social gamification of quizzes conducted during live lectures reported about in this article is a contribution to gamification and relates to audience response systems, competition and cooperation, and peer discussion.

\subsection{Audience response systems}

Audience response systems (ARS) allow lecturers to conduct quizzes during lectures and to provide immediate feedback to both, students and lecturer alike, on the correctness of quiz answers. As the approach introduced in this article is based on a modified ARS, this section establishes the positive effects of ARSs on students' learning.

In their survey of ARSs, Kay and LeSage [12] list various benefits of ARSs: Engagement, attendance, participation, and discussion among them. A meta-analysis conducted by Hunsu et al. [10] found that, among other, the use of ARSs had a positive effect on a number of learning outcomes such as knowledge transfer, but had no effect on other learning outcomes such as retention of the subject matter. ARSs come in form of clickers, that is, students are provided with a physical device that allows them to participate in quizzes, or in form of web-based platforms, which allow students to participate in quizzes using their own internet-capable devices. Examples of web-based ARSs are GoSoapBox [3] and Backstage [1].

\subsection{Gamification}

Deterding et al. define gamification as "the use of game design elements in nongame contexts" [7, p. 10], a definition which leaves "game elements" open to interpretation. This section first establishes the main components of the social-gamified quizzes described in this article - teams and immediate feedback - as game elements and afterwards discusses downsides of gamification.

Teams and Immediate Feedback as Game Elements: Deterding et al. [7] cite Reeves [21] who identifies ten essential elements of games, among others feedback, "competition under rules that are explicit and enforced" [21, p. 80] and teams, and argue that these elements are not in themselves game elements and that it is their contextualization that turns them into game elements. More support for teams and feedback as game elements or gamification mechanisms comes from Nicholson [18] who introduces various dimensions in which "meaningful gamification" can take place, one of them being "engagement" defined as "creating opportunities for participants to engage with others in meaningful ways" [18, p. 12]. According to Nicholson, leaderboards can be part of a gamification utilizing the engagement dimension for allowing comparison. Nicholson also argues that both cooperative and competitive 
elements can be implemented so as to achieve effects similar to those observed in sports: Cooperation within teams and competition between teams. Danelli [5] identifies competition and cooperation as drivers of engagement in various theories about games and play as well.

An example for a study in which teams were introduced into an educational setting is an experiment conducted by Latulipe et al. [14]. A flipped classroom design was adapted: Students studied the content before the lecture during which quizzes were run. By answering those quizzes students could earn points for their team. The authors report on a positive attitude among the students towards the team component.

Kahoot $^{1}$ is an example for an audience response system that includes a team component: Lecturers can create so-called Kahoots, which can be run as quizzes during a classroom session. Quizzes can either be answered by every student on their own or in teams with every team giving a single answer using a single device. Points are awarded depending on answer speed and correctness and after each quiz an updated leaderboard is shown. Optionally, answer streaks, which reward successive correct answers, and a winners' podium, which visualizes the winners at the end of a Kahoot, can be enabled. Esteves et al. [28] evaluated the effects of Kahoot on students' participation and motivation in four university courses. The authors report on positive results, with students stating that using Kahoot was fun and supported understanding of the subject matter. Plump and LaRosa [29] introduced Kahoot into six university courses and report that Kahoot fostered activity and focus in classes and provided all students with a way to contribute to classes. Students mentioned negatively that quizzes were always won by the same students and that chances of recovering after a number of incorrectly answered questions were low. Bicen and Kocakoyun [31] used Kahoot in a university course, adding Kahoots at the end of each lesson. They report on a positive attitude among students towards the gamification and mention among others increased motivation and a supportive atmosphere in the classroom as positive effects of the gamification.

Feedback - especially immediate and continuous feedback - is identified by McGonigal [16] as one of four defining traits of games, goal, rules, and voluntary participation being the other three. An area where gamified feedback is used are cars, e.g., for fostering safe or eco-friendly driving. In [24], a virtual passenger is simulated who reacts to the driver's driving style providing an immediate and tangible feedback to the driver. Feedback on drivers' eco-friendliness can be found in different implementations: From Chevrolet's system that requires to keep a green orb in an optimal position through eco-friendly driving to Ford's EcoGuide that makes the more leaves grow on a display, the eco-friendlier the driving [11]. In all cases, actual optimization criteria are made tangible through a reification of the criterion instead of representing it by an elusive numerical value (expressing, e.g., the fuel consumption).

Downsides of Gamification: While gamification often seems to produce positive results, there is a criticism [18] that most gamification systems are traditional "reward systems" motivating extrinsically (motivated by external rewards [23]) but not intrinsically (motivated by the task itself [23]). Nicholson argues that the positive behav-

\footnotetext{
${ }^{1}$ https://kahoot.com/
} 
iour induced by rewards often stops as soon as the rewards are no longer given if the user has no intrinsic motivation to further perform the task [18]. Indeed, Nicholson observes that there are situations where reward-based gamification can be positive, e.g., when used to teach a skill that has real-live applications because the learner most likely learns to the see the value in the skill itself. Gamification was found to cause higher cognitive load: Turan et al. [30] examined the impact of gamification on cognitive load as well as the impact on academic achievement and students' attitude towards gamification. In their study, one group of students was taught using gamification, the other one using traditional means. Results show a negative influence of gamification on students' cognitive load, but a positive impact on students' achievement as well as a positive attitude among the students towards the gamification. From their results, the authors conclude that cognitive load should be taken into account when designing a form of gamification. In their literature review, Hamari et al. [9] mention three studies that come to the conclusion that gamification has no long-term effects and that positive effects most likely result from its novelty. However, the majority of the studies they examined shows that gamification produces positive results.

In their literature study, Toda et al. identify four negative outcomes of gamification: "Loss of performance", "Undesired Behaviour", "Indifference", and "Declining Effects" [34, p.7 ff.] Andrade et al. identify three further problems of gamification: "Off-Task Behaviour", "Undesired Competition", and "Addiction and Dependence" [33, p. 178 ff.]. To tackle those problems, the authors propose a framework that leverages customization through users and adaptivity using learning analytics to recognize undesired behaviors and to make an appropriate intervention.

\subsection{Competition and co-operation}

Competition, that is, persons trying to attain some goal better or before another person can attain it, and cooperation, that is, a group of persons working together to attain some kind of goal are two concepts that provide the basis for the socialgamified quizzes introduced in this article: Competition between teams and cooperation within teams (see also Nicholson's engagement dimension [18]).

In their meta-analysis of effects of competition on motor performance, Stanne et al. [36] distinguish between two types of competition: "zero-sum competitions", where only one participating party can emerge as winner and "appropriate competition" (by means of criteria formulated by D.W. Johnson and Johnson in two articles and two books which are cited in [36, p. 135]) with its characteristics being the unimportance of winning, reasonable chances to win for everybody, clear and reasonable rules, and the ability of participants to compare themselves with other participants [36]. Cooperation "was found to result in higher performance (...) than competitive or individualistic efforts" [36, p. 144]. Nonetheless, a number of studies "indicate that appropriate structured competition may increase the effectiveness of competition considerably" [36, p. 147], but warn that the number of studies is too low to make a general statement.

Tauer and Harackiewicz [35] examined in various studies the effects of competition coupled with cooperation: Participants which competed with another person (i.e., 
as team) against other teams consistently showed a higher task enjoyment and performance compared to competition between two individuals or cooperation between two individuals without competition, and the majority of participants preferred the competition between teams to the other scenarios. In the same vein, Deutsch states that "competition in a cooperative, playful context can be fun" [37, p. 29].

\subsection{Pedagogical foundation}

The approach to social-gamified quizzes aims to nudge students to discuss the quizzes with their peers and try out the quizzes' code (if applicable). This section introduces research that points to both of those actions having a positive influence on students' learning.

Peer instruction is a term coined and a concept investigated by Eric Mazur [15]. Peer instruction refers to posing questions to a lecture's audience, first asking the students to consider answers on their own, then letting the students discuss the value of their various answers, every student trying to convince their peers of their own answers [4]. The authors report on a positive effect of peer instruction on the learning performance of students. Byrd et al. [2] report on positive effects on academical results from using cooperative quizzes. It is worth stressing that peer instruction in the aforementioned form is hardly possible with lecture audiences of more than a few ten students and almost impossible with audiences of a few hundred.

An approach close to students' discussions of the subjects to learn is "learning by doing". This approach is traditionally deployed in science, technology, engineering, and mathematics (STEM) education. It is justified by Polya who states that humans "acquire any practical skill by imitation and practice" [20, p. 4]. The value for learning by imitation and practice is especially true for programming, a practical skill with deep mathematical foundations.

The importance of imitation and practice is clearly stressed by the emergence of "try-out" environments integrated in various educational software: Some MOOC platforms such as Codeacademy 2 and freeCodeCamp3 make it possible to write and execute code directly from within the learning material. Coding is thus closely integrated into the teaching material and by that into the learning activity. Stack Overflow, a question and answer platform for coding and software development, allows users to directly test answers in the browser if the answers are pieces of code in certain programming languages. Getting students to immediately try out code presented in a lecture is a highly desirable goal, which can hardly be achieved in traditional lectures, because of the students' passivity fostered by that teaching format.

\footnotetext{
${ }^{2}$ https://www.codecademy.com/

${ }^{3}$ https://www.freecodecamp.org/
} 


\section{Team Competition}

The team-based social gamification described in this article makes teams compete against each other in quizzes conducted during lectures. Participants earn points for their team by answering quizzes on their own. During each quiz, a real-time overview of team participation and after each quiz updated team standings are shown to the lecture hall.

\subsection{Team building and reward system}

The core component is a software-supported team-building system that can be adjusted along three axes to fit the actual context it is deployed in:

- Duration: For what time span will the teams exist?

- Formation: Who forms the teams? Teams can be formed by lecturers, the software, or by students themselves.

- Size: How many students are there in a team?

The team building system does not offer one single team configuration expected to fit all situations. Indeed, a team configuration is heavily dependent on the context, and even for a same context, different configurations may make sense.

Another component is the reward system that determines what, and under what circumstances, rewards are given to teams for their members' answers to quizzes. After a quiz, one and only one of the following holds for every student:

- The student participated and answered correctly.

- The student participated and answered incorrectly.

- The student was logged in and did not participate.

- The student was not logged in.

For each of these four outcomes, an effect on the student's team score can be defined. Points awarded for participation act as positive reinforcement (see [25]). Nonparticipating students could be "awarded" negative points what would act as positive punishment (see [25]). Punishing non-participating students could potentially have a stronger impact on participation because of loss aversion (see [26]) but could also demotivate participating team members since it could be perceived as a punishment by those who participated. Indeed, through their team affiliation they would be punished for the actions of others.

\subsection{System}

This section introduces the underlying ARS and its extension with the team-based social gamification described above. The gamification was built as an extension to the existing ARS of the original teaching and learning platform Backstage. ${ }^{4}$ Backstage's

\footnotetext{
${ }^{4}$ https://backstage2.pms.ifi.lmu.de:8080/about
} 
ARS provides the usual features: At any time during a lecture, a quiz can be conducted, students can answer using their laptop, the answers are aggregated, and the aggregated results are displayed in the lecture hall and on the students' screens.

The ARS was extended with an interface displaying in real-time the team participation, an overview of all teams' scores, and a dashboard widget displaying the current team standings. For quizzes, both multiple choice and fill-in-the-blank quizzes were used.

The real-time overview of the team participation can be seen in Figure 1. In this overview, each team is represented by a bar of a bar chart with each bar built from segments representing the team's members. Each segment is colored in one of three colors: White for students who are not logged in, light grey for students who are logged in but have not yet answered, and dark grey for students who have answered. Representing each student as a unique segment serves as immediate feedback and gives students a tangible representation of their contribution or of the absence thereof, respectively.

\section{Participation}

Teams

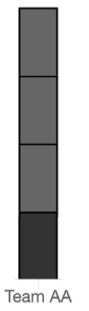

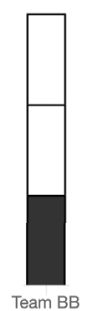

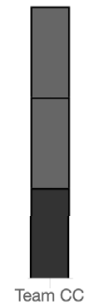

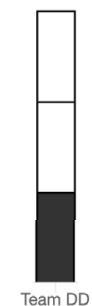

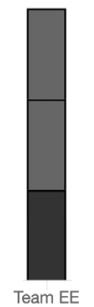

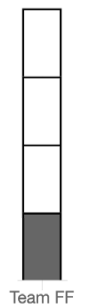

Overall

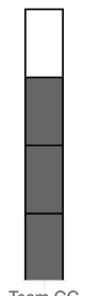

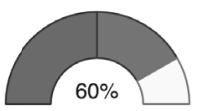

Ans Answer pending

Fig. 1. Real-time overview of team participation shown while a quiz is running.

There are two reasons for including a live overview of team participation: First, a real-time overview of team participation gives lecturers an opportunity to make quizzes more engaging by acting like the moderator of quiz show. As moderator, a lecturer can for example call to participation members of teams with a low participation. Calling out specific teams should have a better impact on the participation than calling out to the whole audience because of diffusion of responsibility, that is, the larger the group, the less responsible individuals feel [6]. While diffusion of responsibility is only researched for smaller group sizes and emergency situations, it is conceivable that the results are transferable to other settings, such as the education setting at hand. Latulipe et al. [14] included a live overview as well, but their implementation only contained the team standings, not a real-time overview of team participation.

Second, a real-time overview of team participation directly influences all students to participate so as to contribute to their teams' score by providing both, intra-group comparisons (that is, how many people of my team have participated?) and intergroup comparisons (that is, how is the participation of the other teams compared to that of my team?). Social comparison theory [8] teaches that people generally aspire 
to reach the performance of people similar to themselves, and one could argue that team members and the rest of the audience fit this criterion. Mekler et al. [17] came to the conclusion that leaderboards - an element allowing comparison - tend to motivate people.

After a quiz has been run, updated team standings - an example of which can be seen in Figure 2 - are displayed to all students what again provides both intra-group and inter-group comparisons. The updated team standings give information on participation and answer correctness both for each team and for the whole lecture hall as well as possible changes in team placements.

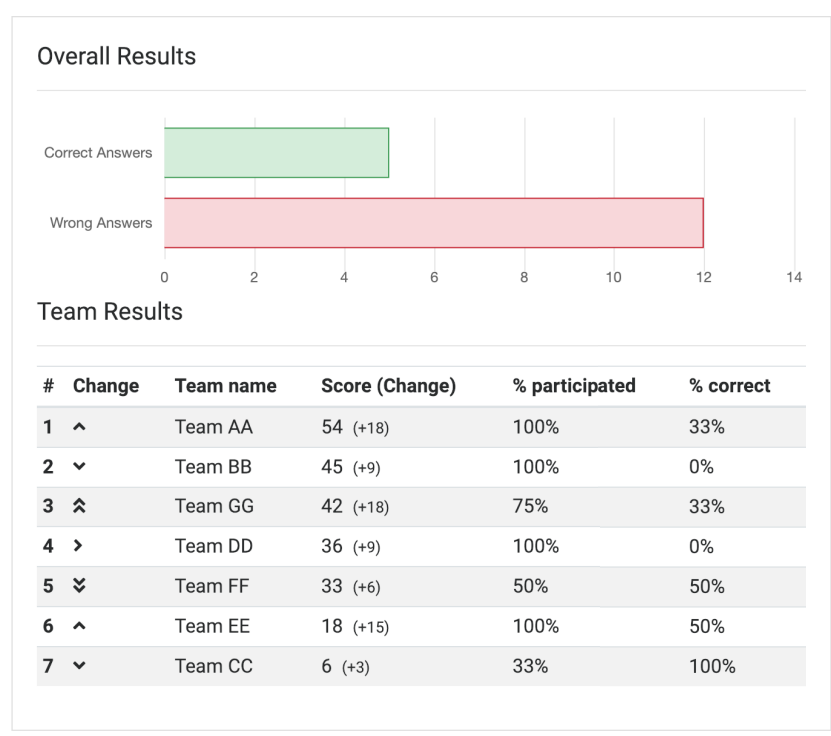

Fig. 2. Classroom (top) and team results (bottom) shown after a quiz has been run.

On their own screen, every student is provided with an overview displaying their given answers, the correct answers, and how many points they have contributed to their team's score, again, providing a tangible and personalized feedback. Additionally upon logging into Backstage, every student is provided with an overview of the current team standings in form of a dashboard element.

\section{Evaluation}

Evaluations on the effects of the team-based social gamification of quizzes on participation in quizzes and attendance at lectures have been conducted in two presence courses with different configurations of the team component.

- C1: A course accompanying a practical on software development in which students were tasked to develop a browser-based game in the programming language JavaScript in groups of three to four students. Those groups were created by the 
lecturers and used as teams for the quizzes run during the lecture as well. The course consisted of one weekly lecture lasting two hours.

- C2: A course on logic and discrete mathematics. The gamification was used for the second part of the lecture about discrete mathematics. Every student was randomly assigned to one of four teams. The course consisted of one weekly lecture lasting three hours.

Table 1. Overview of the utilization of the team component in C1 and C2. L1, L2, L3, and L4 describe the time-sorted lectures in which the team-based social gamification was used.

\begin{tabular}{|l|c|c|l|c|c|c|c|}
\hline Course & \multirow{2}{*}{$\begin{array}{c}\text { Number of } \\
\text { participants }\end{array}$} & \multirow{2}{*}{$\begin{array}{c}\text { Number } \\
\text { of teams }\end{array}$} & \multirow{2}{*}{$\begin{array}{c}\text { Mode of team } \\
\text { distribution }\end{array}$} & \multicolumn{4}{|c|}{ Number of quizzes } \\
\cline { 5 - 8 } & 24 & 7 & Lecturer & 6 & 4 & 3 & 4 \\
\hline C1 2 & 603 & 4 & $\begin{array}{l}\text { Randomly by } \\
\text { software }\end{array}$ & 6 & 5 & 5 & 6 \\
\hline
\end{tabular}

In C2, every student was automatically assigned a team when first registering for the course on Backstage. Therefore, this number includes both users who never visited a single lecture as well as users that joined the course only days before the examination.

In both courses, correct answers were rewarded with 12 points, participation (regardless of the answers' correctness) with 3 points. Every other action of a student had no effect on a student's team's score.

The competition that took part in both courses can be classified as appropriate:

- Winning had no other effect than being the number one in the leaderboard, therefore winning was of no great importance.

- Every team had similar chances of winning: In C1 teams were formed by the lecturer to be comparable in ability and in $\mathrm{C} 2$, teams were formed randomly which creates teams of similar ability provided a large enough number of participants.

- In both cases, rules were clearly communicated and straightforward.

- Comparisons for both inter- and intra-group comparisons were (see Section 3).

\subsection{Methods}

Two data sources were polled so as to evaluate the effects of the team-based social gamification on the participants of the courses: the ARS and a survey. In C1 the survey was conducted during the final lecture of the course, and in C2 an online survey was conducted after the examination which took place after the course's end. In both courses, the same questions were used:

- A first group of questions referred to the student's course of study, current semester, and gender.

- A second block of questions aimed at measuring how the team-based social gamification impacted on the motivation.

- A third block of questions aimed at measuring the engagement brought by the team-based social gamification. 
- A fourth block of questions collected self-assessments of participation.

- C1: Two questions with free-text answers allowed students to give further feedback.

C2: One question to be answered with free-text asked whether students felt that teams are suitable for making large class lectures more engaging.

For $\mathrm{C} 1$, the answers to the second, third, and fourth block were given on a 4-point answer scale from strongly agree to strongly disagree with no neutral choice. For C2, the answers were given on a 6-point answer scale from strongly agree to strongly disagree. The reason for using another scale is that the questions were part of larger questionnaire, which needed that other scale. The results for $\mathrm{C} 2$ were rescaled to the scale of the survey for $\mathrm{C} 1$ to allow comparability. A question asking if students tried out quizzes' code was omitted for $\mathrm{C} 2$, as this lecture did not include any programming quizzes.

Data collected directly from the system included quiz participation, team affiliation, and the history of team standings.

\subsection{Results}

For $\mathrm{C} 1$, the data acquired from the system refers 22 students for the first lecture and 24 students for all subsequent lectures. The reason for the difference in numbers is that two students had not yet registered when the first lecture took place. In the last lecture, a total of 19 students took part in the survey, 9 of them were female and 10 male. The students' current semester ranged from 2 to 8 . For $\mathrm{C} 2$, the data acquired from the software refers to 603 students. The survey was filled out by 17 students, 16 (sometimes 15) of which answered the parts on the team component. 8 of the students were female, 8 of them male, and their current semester ranged from 1 to 10 .

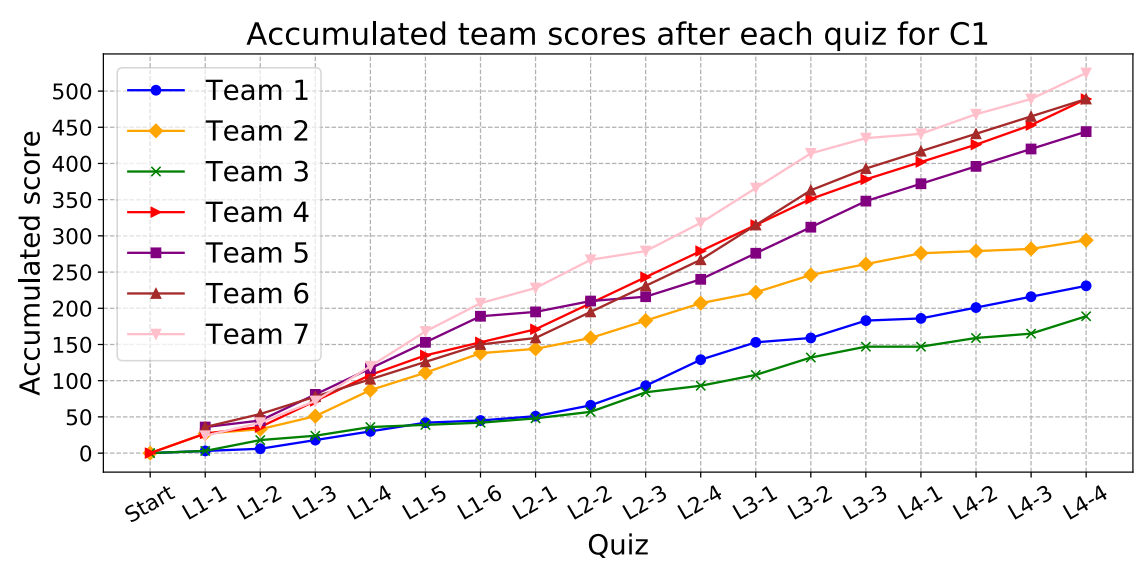

Fig. 3. Development of the accumulated team scores after each quiz for $\mathrm{C} 1$. 


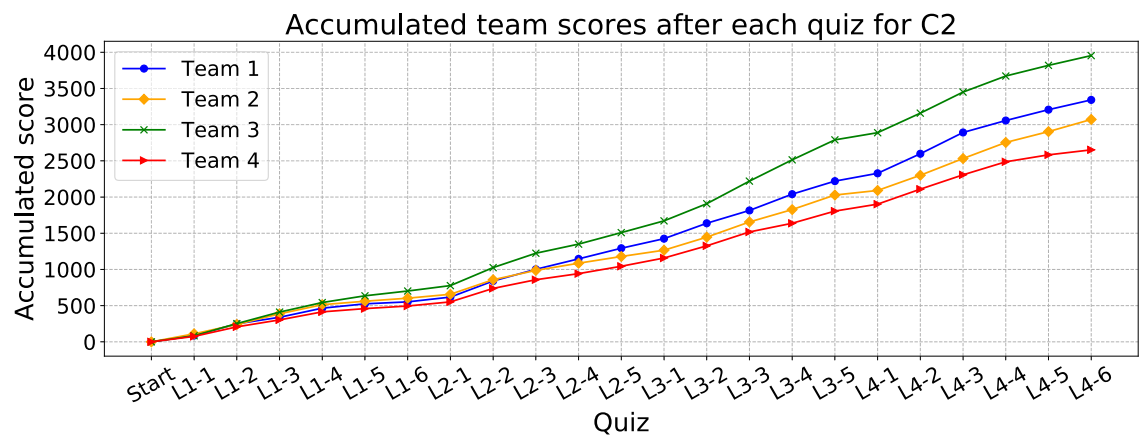

Fig. 4. Development of the accumulated team scores after each quiz for $\mathrm{C} 2$.

In Figure 3 and 4, the team standings after each quiz for $\mathrm{C} 1$ and $\mathrm{C} 2$ can be seen. For $\mathrm{C} 1$, there are two groups: A leading group consisted of Team 4, Team 5, Team 6 , and Team 7 - those teams participated in the competition for a place on the winners' podium. Team 1, Team 2, and Team 3 are far behind: While Team 2 was competitive until the beginning of the third lecture, the gap between its score and the leading group's scores grew steadily. Teams 1 and Team 3 show a nearly identical progression, the performance gap between those teams being caused by the last quiz of the second lecture. The competition ended with four teams on the winners' podium, as the race between Team 4 and Team 6 ended in a draw. On the other hand, the team standings after each quiz for $\mathrm{C} 2$ do not exhibit such patterns: The teams' progressions look nearly identical, the only difference being the team standings' slopes.

Table 2. Team participation in quizzes over the time-sorted lectures for $\mathrm{C} 1$.

\begin{tabular}{|l|c|c|c|c|c|c|c|c|}
\hline \multicolumn{1}{|c|}{ Team } & Team 1 & Team 2 & Team 3 & Team 4 & Team 5 & Team 6 & Team 7 & Avg. \\
\hline Sizes & 3 & 4 & 3 & 3 & 3 & 4 & 4 & - \\
\hline L1 & 0.33 & 0.67 & 0.67 & 1.00 & 1.00 & 0.78 & 0.88 & 0.76 \\
\hline L2 & 0.83 & 0.50 & 0.92 & 1.00 & 0.67 & 0.75 & 1.00 & 0.81 \\
\hline L3 & 0.67 & 0.50 & 0.67 & 1.00 & 1.00 & 1.00 & 1.00 & 0.83 \\
\hline L4 & 0.58 & 0.31 & 0.41 & 0.83 & 0.67 & 0.50 & 0.75 & 0.58 \\
\hline Average & 0.60 & 0.50 & 0.67 & 0.96 & 0.84 & 0.76 & 0.91 & 0.75 \\
\hline
\end{tabular}

Table 3. Team participation in quizzes over the time-sorted lectures for $\mathrm{C} 2$.

\begin{tabular}{|l|c|c|c|c|c|}
\hline \multicolumn{1}{|c|}{ Team } & Team 1 & Team 2 & Team 3 & Team 4 & Avg. \\
\hline Sizes & 151 & 151 & 151 & 150 & - \\
\hline L1 & 0.11 & 0.11 & 0.13 & 0.08 & 0.11 \\
\hline L2 & 0.15 & 0.13 & 0.17 & 0.11 & 0.14 \\
\hline L3 & 0.15 & 0.13 & 0.18 & 0.11 & 0.14 \\
\hline L4 & 0.14 & 0.13 & 0.15 & 0.10 & 0.13 \\
\hline Average & 0.14 & 0.13 & 0.16 & 0.10 & 0.13 \\
\hline
\end{tabular}

Table 2 and 3 show team participation over the time-sorted lectures for $\mathrm{C} 1$ and $\mathrm{C} 2$ : In both courses, participation increased after the first lecture. After that, the participa- 
tion in C1's quizzes increased further, before dropping sharply in the last lecture. In $\mathrm{C} 2$, participation remained unchanged in the third lecture, before slightly dropping in the last lecture. The difference in magnitude between the courses' participation is caused by the way participation was calculated and the time the courses took place. $\mathrm{C} 1$ took place during the first six weeks of the term, while C2 took place in the last five weeks of the term where attendance is generally lower. For calculating participation, all students registered by the end of the course were taken as total: In C2, students could join at will, therefore the number includes students never visiting a single lecture as well. In $\mathrm{C} 1$, students were manually admitted to the course by the lecturers.

While the average participation shows a rise in both cases, with two exceptions (Team 4 and Team 7) individual team participations in $\mathrm{C} 1$ follow different trends. Nonetheless, four of the seven teams in $\mathrm{C} 1$ and two out of four teams in $\mathrm{C} 2$ beat the average participation.

Table 4 shows the survey results for both courses: In $\mathrm{C} 1$, all components of the team competition motivated the students to similar degrees, while in $\mathrm{C} 2$ only the live overview was reported as a motivating component (Block 2). In C1, the team-based social gamification fostered engagement with students reporting that they discussed the answers with their team members before answering and testing the quizzes' code as well. Students in $\mathrm{C} 1$ reported that the team component made the lecture more engaging and fun. The results for $\mathrm{C} 2$ are the opposite: Students did not feel inclined to discuss answer options and neither did they thought the team component to make the lecture more engaging nor fun (Block 3). In both courses, the majority of the students reported that they would have taken part in the quizzes and brought a device even without team competition. In $\mathrm{C} 1$, three students agreed with the statement that they would not have brought a device without the teams; that number was zero for $\mathrm{C} 2$. Students in $\mathrm{C} 1$ prefer quizzes solved in teams over both, quizzes without teams and points and quizzes without teams and points, while the students in C2 would have preferred to solve the quizzes without teams but with points (Block 4).

Table 4. Survey results for both courses. Strong agree was assigned a value of 4 , agree a value of 3 , disagree a value of 2 , and strong disagree a value of 1 .

\begin{tabular}{|c|c|c|c|c|}
\hline \multirow{2}{*}{ Statement } & \multicolumn{2}{|c|}{ C1 $(n=19)$} & \multicolumn{2}{|c|}{$C 2(n=15-16)$} \\
\hline & Mean & $S D$ & Mean & $S D$ \\
\hline \multicolumn{5}{|c|}{ Block 2: Motivating Components } \\
\hline Motivated by the live overview of submitted responses & 3.32 & 0.75 & 2.84 & 1.05 \\
\hline Motivated by competition with other teams & 3.16 & 0.83 & 1.98 & 0.84 \\
\hline Motivated by the chance to contribute to team's score & 3.21 & 0.71 & 1.96 & 0.96 \\
\hline \multicolumn{5}{|c|}{ Block 3: Engagement through Team Component } \\
\hline Lecture became more engaging through the team component & 3.16 & 0.69 & 2.09 & 0.96 \\
\hline Discussed answers with the team to get answer correct & 3.21 & 0.63 & 2.05 & 0.94 \\
\hline Tried out quiz' code before answering to get answer correct & 2.79 & 0.63 & - & - \\
\hline Competition was fun & 3.16 & 0.60 & 2.16 & 1.02 \\
\hline \multicolumn{5}{|c|}{ Block 4: Participation without Team Component } \\
\hline Would have participated without team component & 3.16 & 0.83 & 3.59 & 0.48 \\
\hline Would have brought device without team component & 3.16 & 0.83 & 3.63 & 0.43 \\
\hline Would prefer to solve on my own without points & 1.90 & 0.57 & 2.31 & 0.70 \\
\hline Would prefer to solve on my own with points & 1.84 & 0.69 & 3.00 & 0.81 \\
\hline
\end{tabular}


In C2's survey, 9 students provided answers to the question whether they find teams suitable for bringing engagement to large class lectures. Four of them found the implementation of teams unsuitable because they and their friends (or persons sitting next to them) were not put in the same teams ("I go to university with a group of friends \& we all got put into different teams"), three students mentioned that random assignment of teams inhibited the creation of team spirit as students did not know who was in their team ("Team spirit can only be built up if you know your team members"). Two students thought that teams are suitable for bringing engagement to large class lectures, one student found the scoring system to be unfair, as teams with more participating members were automatically awarded more points, and a single student mentioned that they do not like competing and therefore did not like the teams.

\subsection{Discussion}

The results indicate that the impact of a team-based social gamification is dependent on the configuration and context of its deployment. In $\mathrm{C} 1$, a small course with small teams, the team-based social gamification had a positive impact on participation in and on engagement during lectures. On the other hand, in C2, a large class with randomly assigned large teams, the team-based social gamification failed to foster any kind of engagement.

Looking at the team standings for $\mathrm{C} 1$ given in Figure 2, it becomes evident that the team-based social gamification of quizzes introduced competition: Indeed, there are overtakes (L2-2 in Figure 2 where Team 4 and Team 6 overtook Team 5) and comebacks (Team 6 overtook Team 4 at point L3-1 which caught up again at point L4-1). While the team standings are not definitive indicators of how students perceived competition, the survey results clearly show that students perceived a competition introduced by teams and were motivated by that competition. On the other hand, the team standings for $\mathrm{C} 2$ given in Figure 3 do not show any kind of competition: Generally, the team standings over time follow all the same trend, with not a single overtake or comeback happening. Cooperation and collaboration only took place in $\mathrm{C} 1$, where the majority of students discussed their answers within their team before submitting them. Students in C2 did not feel inclined to discuss their answers with their team mates, which most likely was caused by the randomly assigned teams - team mates were distributed over the whole lecture hall and not necessarily sitting in close proximity to each other, which is a precondition for discussion.

In both cases, participation in quizzes increased over time, with either dropping very slightly $(\mathrm{C} 2)$ or sharply $(\mathrm{C} 1)$ in the last lecture session. The sharp drop in participation in $\mathrm{C} 1$ could be interpreted as the positive effects of team-based social gamification being short lived, but the authors presume a different reason the structure of the practical required students to actively start coding from the first week. Due to bank holidays, the fourth lecture took part in the sixth week of the term at which most teams were already deeply involved in the project and probably had already learnt the topics of the fourth lecture, therefore not seeing the point in paying attention and participating in quizzes. Indeed, during the last lecture, students trickled in throughout 
the session, and at the end, only 19 students attended the lecture, which was an exception because for all previous lectures, at most four students were skipping class. Survey results indicate that the increase in participation can partly be attributed to the social gamification as a small number of students brought their device and were motivated to participate in quizzes because of the gamification. While participation in $\mathrm{C} 2$ follows (with the exception of the last lecture) a similar trend, this cannot be attributed to the gamification as the survey has shown that zero students were motivated by the gamification to bring their device or participate in quizzes. The authors presume that the sudden introduction of an ARS in the middle of the semester took students by surprise and students began to bring devices to participate in quizzes in subsequent lectures, which led to the increase starting with the second lecture.

Nonetheless, results for $\mathrm{C} 1$ show a difference between the course of the average participation and the course of teams' individual participation, which may be explained by not everyone liking teams: Two participants of $\mathrm{C} 2$ rather disagreed with the statement that the competition was fun and three participants rather disagreed with the statement that teams made the lecture more engaging. Non-participation of those students would have a rather big effect on the team's average, while non-participation of few members in big teams would not have as big as an impact.

The survey shows that the competition had a motivating impact on the students in $\mathrm{C} 1$ with each of the survey items in the category motivation (Block 2) ranging from agree to strongly agree. According to the survey's results, the strongest motivating factor for participation was the real-time overview. The motivating impact of the live overview is backed by the results from $\mathrm{C} 2$ : While all other components of the competition failed to motivate students, students tended to agree that the live overview motivated them to participate. Thus, the results of the evaluations suggest that the overview worked exactly as intended.

While students in $\mathrm{C} 1$ perceived the gamification of quizzes as fun, students in $\mathrm{C} 2$ did not feel that way. A possible explanation for that is the lack of identification with one's own team as well as the distribution of team members over the whole lecture hall as suggested by the students' answers to the free text question.

Students in $\mathrm{C} 1$ favored the competition introduced by teams over answering quizzes on their own and without being rewarded points. In $\mathrm{C} 2$, students would have preferred to solve quizzes on their own and being rewarded points. These results suggest that students of both groups would like their lecture hall to be gamified, but that in $\mathrm{C} 2$, the chosen gamification failed to do so appropriately. Furthermore, there seems to exist not one configuration or gamification fitting all contexts, and that for the teambased social gamification, the chosen team configuration seems to be the crux of the matter.

The team configuration chosen for $\mathrm{C} 2$ failed to evoke any kind of fun and engagement in the students, which may potentially be explained by the differences between the courses: Large, mostly anonymous teams inhibit the development of team spirit which is backed by the answers to the free text question in C2's survey: The majority of participants (who provided an answer) felt that the use of teams in $\mathrm{C} 2$ did not facilitate the development of team spirit or any kind of team identification, as students were not aware who was in their teams, friends were put into different teams, and 
teams were distributed all over the lecture hall. As the participants generally expressed interest in gamification, the following section introduces improvements to the team component which addresses the criticisms expressed by $\mathrm{C} 2$ 's participants.

\section{$5 \quad$ Adapting Team-Building to Large Classes}

The results from Section 4 show that the social-gamified quizzes failed to have an impact on the audience of the examined large class lecture. Reasons for that were already discussed in the previous section: team members' mostly remaining strangers for the duration of the course, friends not being put in the same team, and team members being distributed over the whole lecture hall, instead of being in close proximity. Hence, teams in large classes should be formed in a way that addresses those issues, which should support the building of team spirit and identification.

One approach which fulfils those conditions is to let students chose their own teams, which would allow friends to join the same teams, alleviating the problem of anonymous teams, but would lead in large classes to a large number of teams, which no longer could be presented in a clear manner in the team standings and the live overview. Increasing team sizes would solve this problem, but would introduce organizational and communicational issues, as students would have to first settle on a team with the students in their proximity and afterwards propagate the decision to all students in their proximity. To make a small number of large teams work in large class lectures, the physical location of the students in the lecture hall can be exploited.

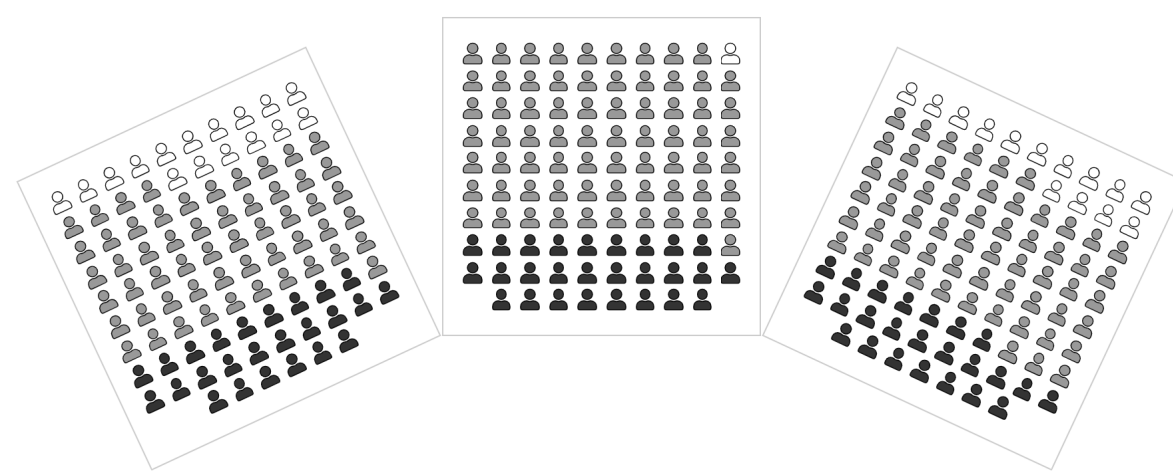

Fig. 5. Mockup of the live overview when teams are assigned parts of a lecture hall with each student being represented by an icon. White icons represent students who are not logged in, light grey icons represent students who are logged in but have not yet answered, and dark grey icons represent students who have answered.

The lecture hall where the course took place (and will take place in the next term) consists of three blocks or "wings", all three having approximatively the same number of seats. Assigning each wing a team alleviates all of the stated problems: it is rather clear which team a student belongs to; team members are no longer necessarily strangers and in close proximity to each other, and friends are in the same team be- 
cause it is likely that they sit next to each other. Figure 5 shows a possible visualization of the live overview: The lecture hall is shown as a schematic overview and each student is represented by an appropriately colored icon in the respective wing. Configuring and adapting the team component in such a way should alleviate most of the criticisms expressed by students of the large class lecture.

\section{Perspectives and Outlook}

Learning in STEM lectures is often hindered by a low level of student activity during lectures what negatively impacts learning. To address this drawback of traditional lectures and make lectures with audiences of varying size more interactive, this article introduced a team-based social gamification. With this approach, teams compete in quizzes run during lectures, the individual participation of a student to quizzes contributing to their team's score. Two evaluations paint different pictures of the approach's effectiveness: While the approach was effective in a small class lecture, fostering participation during, and therefore enhancing engagement to lectures, it failed to foster participation and engagement in a large class lecture. Possible reasons for that have been suggested by an analysis of the evaluation and - building upon that analysis - an updated approach for large classes was proposed.

Other avenues for future work include the addition of further game elements, such as power ups, e.g., double a team's earned points for the next quiz. Furthermore, the reward system should be adjusted so as to avoid giving larger teams an advantage over smaller teams. Such an adjustment could be extended to take into account the number of participating students as well, removing the "punishment" for not attending the lecture. This removal is likely to counterbalance demotivating effects on the participating students, as they are no longer punished for other students' absence, yet removing the incentive to attend the lecture for those absent students.

Gamification injected directly in traditional lectures has the potential to make lectures more fun and more engaging for students - two factors of more positive learning outcomes. This article has demonstrated that the team-based social gamification can bring fun and engagement into small lectures and proposed an approach to make team-based social gamification work in large class lectures.

\section{$7 \quad$ Acknowledgement}

The authors are thankful to Jacob Fürst for the implementation of the quizzes and the groundwork for the team-based social gamification described in the article, which he did as part of his unpublished bachelor's thesis. The authors would like to thank the reviewers for their comments and suggestions. 


\section{$8 \quad$ References}

[1] Bry, F. and Pohl, A.Y.S., 2017. Large class teaching with Backstage. Journal of Applied Research in Higher Education, 9(1), pp.105-128. https://doi.org/10.1108/JARHE-06-2015$\underline{0042}$

[2] Byrd, G.G., Coleman, S. and Werneth, C., 2004. Exploring the universe together: Cooperative quizzes with and without a classroom performance system in Astronomy 101. Astronomy Education Review, 3(1), pp.26-30. https://doi.org/10.3847/AER2004004

[3] Carroll, J.A., Rodgers, J., Sankupellay, M., Newcomb, M. and Cook, R., 2014. Systematic evaluation of GoSoapBox in tertiary education: a student response system for improving learning experiences and outcomes. INTED2014 Proceedings.

[4] Crouch, C.H. and Mazur, E., 2001. Peer instruction: Ten years of experience and results. American journal of physics, 69(9), pp.970-977. https://doi.org/10.1119/1.1374249

[5] Danelli, F., 2015. Implementing game design in gamification. In Gamification in education and business (pp. 67-79). Springer, Cham. https://doi.org/10.1007/978-3-319-10208-5 4

[6] Darley, J.M. and Latané, B., 1968. Bystander intervention in emergencies: diffusion of responsibility. Journal of personality and social psychology, 8 (4p1), p.377.

[7] Deterding, S., Dixon, D., Khaled, R. and Nacke, L., 2011, September. From game design elements to gamefulness: defining gamification. In Proceedings of the 15 th international academic MindTrek conference: Envisioning future media environments (pp. 9-15). ACM.

[8] Festinger, L., 1954. A theory of social comparison processes. Human relations, 7(2), pp.117-140. https://doi.org/10.1177/001872675400700202

[9] Hamari, J., Koivisto, J. and Sarsa, H., 2014, January. Does gamification work?--a literature review of empirical studies on gamification. In 2014 47th Hawaii international conference on system sciences (HICSS) (pp. 3025-3034). IEEE.

[10] Hunsu, N.J., Adesope, O. and Bayly, D.J., 2016. A meta-analysis of the effects of audience response systems (clicker-based technologies) on cognition and affect. Computers \& Education, 94, pp.102-119. https://doi.org/10.1016/j.compedu.2015.11.013

[11] Inbar, O., Tractinsky, N., Tsimhoni, O. and Seder, T., 2011, May. Driving the scoreboard: Motivating eco-driving through in-car gaming. In Proceedings of the CHI 2011 Workshop Gamification: Using Game Design Elements in Non-Game Contexts (pp. 07-12).

[12] Kay, R.H. and LeSage, A., 2009. Examining the benefits and challenges of using audience response systems: A review of the literature. Computers \& Education, 53(3), pp.819-827. https://doi.org/10.1016/j.compedu.2009.05.001

[13] Kelly, G.E., 2012. Lecture attendance rates at university and related factors. Journal of Further and Higher Education, 36(1), pp.17-40. $\underline{\text { https://doi.org/10.1 }}$ $\underline{\text { 080/0309877X.2011.596196 }}$

[14] Latulipe, C., Long, N.B. and Seminario, C.E., 2015, February. Structuring flipped classes with lightweight teams and gamification. In Proceedings of the 46th ACM Technical Symposium on Computer Science Education (pp. 392-397). ACM.

[15] Mazur, E., 2017: Peer instruction. Springer. https://doi.org/10.1007/978-3-662-54377-1

[16] McGonigal, J., 2011. Reality is broken: Why games make us better and how they can change the world. Penguin.

[17] Mekler, E.D., Brühlmann, F., Opwis, K. and Tuch, A.N., 2013, October. Do points, levels and leaderboards harm intrinsic motivation? An empirical analysis of common gamification elements. In Proceedings of the First International Conference on gameful design, research, and applications (pp. 66-73). ACM. https://doi.org/10.1145/2583008.2583017

[18] Nicholson, S., 2015. A recipe for meaningful gamification. In Gamification in education and business (pp. 1-20). Springer, Cham. https://doi.org/10.1007/978-3-319-10208-5_1 
[19] Pohl, A., 2015. Fostering awareness and collaboration in large-class lectures: principles and evaluation of the Backchannel Backstage (Doctoral dissertation, Ludwig-MaximiliansUniversität München).

[20] Polya, G., 2004. How to solve it: A new aspect of mathematical method (No. 246). Princeton university press.

[21] Reeves, B. and Read, J.L., 2009. Total engagement: How games and virtual worlds are changing the way people work and businesses compete. Harvard Business Press.

[22] Russell, G. and Shaw, S., 2009. A study to investigate the prevalence of social anxiety in a sample of higher education students in the United Kingdom. Journal of Mental Health, 18(3), pp.198-206. https://doi.org/10.1080/09638230802522494

[23] Ryan, R.M. and Deci, E.L., 2000. Intrinsic and extrinsic motivations: Classic definitions and new directions. Contemporary educational psychology, 25(1), pp.54-67. https://doi.org/10.1006/ceps.1999.1020

[24] Shi, C., Lee, H.J., Kurczak, J. and Lee, A., 2012, October. Driving infotainment app: gamification of performance driving. In Adjunct Proceedings of the 4th International Conference on Automotive User Interfaces and Interactive Vehicular Applications (pp. 26-27).

[25] Skinner, B.F., 2011. About behaviorism. Vintage.

[26] Tversky, A. and Kahneman, D., 1991. Loss aversion in riskless choice: A referencedependent model. The quarterly journal of economics, 106(4), pp.1039-1061. https://doi.org/10.2307/2937956

[27] Voelkl, K.E., 1995. School warmth, student participation, and achievement. The journal of experimental education, 63(2), pp.127-138. https://doi.org/10. $\underline{1080 / 00220973.1995 .9943817}$

[28] Esteves, M.D., Pereira, A., Veiga, N., Vasco, R. and Veiga, A., The Use of New Learning Technologies in Higher Education Classroom: A Case Study. International Journal of Engineering Pedagogy (iJEP), 8(2), pp.115-127.

[29] Plump, C.M. and LaRosa, J., 2017. Using Kahoot! In the classroom to create engagement and active learning: a game-based technology solution for elearning novices. Management Teaching Review, 2(2), pp.151-158. https://doi.org/10.1177/2379298116689783

[30] Turan, Z., Avinc, Z., Kara, K. and Goktas, Y., 2016. Gamification and education: Achievements, cognitive loads, and views of students. International Journal of Emerging Technologies in Learning (iJET), 11(07), pp.64-69. https://doi.org/10. 3991/ijet.v11i07.5455

[31] Bicen, H. and Kocakoyun, S., 2018. Perceptions of Students for Gamification Approach: Kahoot as a Case Study. International Journal of Emerging Technologies in Learning (iJET), 13(02), pp.72-93. https://doi.org/10.3991/ijet.v13i02.7467

[32] Mader S, Bry F., 2019. Gaming the Lecture Hall: Using Social Gamification to Enhance Student Motivation and Participation. In Proceedings of the 21st International Conference on Interactive Collaborative Learning, to appear.

[33] Andrade, F.R., Mizoguchi, R. and Isotani, S., 2016, June. The bright and dark sides of gamification. In International conference on intelligent tutoring systems (pp. 176-186). Springer, Cham. https://doi.org/10.1007/978-3-319-39583-8_17

[34] Toda, A.M., Valle, P.H. and Isotani, S., 2017, March. The dark side of gamification: An overview of negative effects of gamification in education. In Researcher Links Workshop: Higher Education for All (pp. 143-156). Springer, Cham. https://doi.org/10.1037/0022$\underline{3514.86 .6 .849}$

[35] Tauer, J.M. and Harackiewicz, J.M., 2004. The Effects of Cooperation and Competition on Intrinsic Motivation and Performance. Journal of Personality and Social Psychology, 86(6), pp.849-861. 
[36] Stanne, M.B., Johnson, D.W. and Johnson, R.T., 1999. Does Competition Enhance or Inhibit Motor Performance: A Meta-analysis. Psychological Bulletin, 125(1), pp.133-154. https://doi.org/10.1037/0033-2909.125.1.133

[37] Deutsch, M., 2011. Cooperation and competition. In Conflict, interdependence, and justice (pp. 23-40). Springer, New York, NY. https://doi.org/10.1007/978-1-4419-9994-8 2

\section{Authors}

Sebastian Mader is a research associate at the Institute for Informatics at Ludwig Maximilian University of Munich, Germany.

François Bry is a full professor at the Institute for Informatics at Ludwig Maximilian University of Munich, Germany.

This article is a revised version of a paper presented at the International Conference on Interactive Collaborative Learning (ICL2018), held September 2018, in Kos, Greece. Article submitted 2019-01-16. Resubmitted 2019-03-11. Final acceptance 2019-03-11. Final version published as submitted by the authors. 